\title{
Concepts and Challenges in Digital Scholarship
}

\author{
Eileen Scanlon* \\ Institute of Educational Technology, The Open University, Milton Keynes, United Kingdom
}

Keywords: digital scholarship, interdisciplinarity, academic practice, communication, scholarship of teaching and learning

\section{INTRODUCTION}

The concept of digital scholarship is much discussed. Most writing on scholarship takes its cue from the work of Boyer (1990). Boyer was a senior figure in higher education, at one point Chancellor of the State University of New York who developed an account of what it means to be a scholar. He developed a view on teaching and research activities in the modern university and came up with a conceptualization of scholarship encompassing four-dimensional functions [described as follows in Scanlon (2013) (p. 13)]:

- discovery, the creation of new knowledge in a specific area or discipline,

- integration, creating knowledge across disciplines,

- application, engagement with the wider world outside academia, but still based on the scholar's disciplinary knowledge and background, and

- teaching, applying scholarship to inform teaching.

What Boyer was considering in his account of scholarship was the working of an individual university. To some degree, his account was designed as a corrective to his perception that time spent by faculty on research (an idea that was only introduced to universities in America in the early years of the twentieth century) was at the expense of time that could be spent on teaching and other academic service. He introduced the idea that a wider conceptualization of scholarship would properly encompass other aspects of the legitimate and desirable activities of a university. He was also aware of the potential overlap between the categories or functions of scholarship and saw the need for a holistic view of scholarship:

The work of the scholar also means stepping back from one's investigation, looking for connections, building bridges between theory and practice, and communicating one's knowledge effectively to students. (Boyer, 1990, p. 16)

This article was submitted to Digital Scholarship, a section of the journal Frontiers in Digital Humanities

Received: 04 May 2016

Accepted: 03 July 2017

Published: 27 July 2017

Citation:

Scanlon E (2017) Concepts and Challenges in Digital Scholarship.

Front. Digit. Humanit. 4:15. doi: 10.3389/fdigh.2017.00015

This work on scholarship has been very influential. It led to further consideration of how the different aspects of scholarship could be improved or measured. In terms of the scholarship of teaching, it was an important move to emphasize that it is not the same as teaching itself. Successive commentators have elaborated on the important features of the scholarship of teaching being public, open to critique and evaluation and conducted in a form upon which others can build [see, e.g., Friesen et al. (2016)]. Another example of elaboration is that of Glassick et al. (1997) and Glassick (2000). These developed some assessment criteria for application to each of the categories described above. There have been several points made by commenters on this influential contribution to the purposes of a university. For some commenters, as the context is limited to level of the individual university, this can prevent or limit understanding of the links between scholarship and working with other 
institutions and the broader global knowledge learning system [see, e.g., Johnston (1998) and Borgman (2007)].

However, there is a need to revisit these categories of scholarship. In the view of Johnston:

Knowledge has expanded and new subjects continue to form as disciplines connect and overlap the scholarship of integration becomes more important. (Johnston 1998, p. 260)

Boyer's focus on the individual academic scholar [see, e.g., Pearce et al. (2010)] means that direct insight from his work into networks of digital scholarship or institutional engagement with digital scholarship is limited. However, he also was aware of the importance of collaboration and networks:

The connectedness of things is what a university is all about, and I believe the great university of the future will be described as a community of scholars. [extract from Boyer (1994)]

There are some aspects of Boyer's framework that have troubled some researchers. Some dimensions of the framework do overlap especially when the digital turn enters into the discussion of categories of scholarship. One example is the relationship between the use of open educational resources (OER) for teaching and open access for publishing research. McAndrew et al. (2010) cite the work of Borgman (2007) that points to several new capabilities offered by information technology at different stages of research projects and the potential shifts in the system of scholarly communication, publishing in journals, books, and conference proceedings. As a consequence they wonder "whether the open practices developed in relation to the use of OER (open educational resources) for teaching have any impact on the extent to which researchers value the open access movement for scholarly publishing or vice versa" (McAndrew et al., 2010).

Colebeck and Michael (2006) discuss the way that public scholarship could provide for a focus and way of integrating Boyer's four domains of scholarship.

Academic work need not be subdivided.... Individual faculty may conduct academic work in an integrated way, using their research to inform their teaching, their service and teaching as sources of ideas for their research, and their teaching as opportunities to provide service to the community as well as foster student learning. (Colebeck and Michael, 2006, p. 10)

There is potentially an artificial divide between the four domains of scholarship as originally outlined by Boyer and an increasing understanding of the different stages of scholarship. These stages can include the formation of projects, the processes by which they proceed and are advanced and the output stage. The output stage can include increasingly varied and differentiated outputs of research, and more nuanced types of impact on society whether on teaching within the University and the formation of curricula, whether by journals, books or conference proceedings or more informal methods of communication, or by impact on the application of research findings to interdisciplinary problemsolving. One small example of this is the shift toward considering the data collected with projects itself as a research output [see, e.g., Borgman (2007) and Pearce et al. (2010)].

The move to the digital context suggests that the boundaries between stages can be overstated (Boyer accepted the categories were overlapping) and are likely to be blurred even further. Another aspect of the Boyer framework in the contemporary landscape which needs further consideration is that the "teaching" dimension should include the learning of new skills (particularly those required for digital scholarship). Scanlon (2013) discusses a research project during which an expanded working definition of digital scholarship was produced which builds on, but also seeks to address, some of the limitations of Boyer's framework.

\section{THE INFLUENCE OF TECHNOLOGY ON THE MOVE TO DIGITAL SCHOLARSHIP}

All activities are changed by the introduction of technology. Scholarship is no exception. A useful theoretical perspective on the way human activity is influenced by technology is provided by Cultural Historical Activity Theory (Engeström, 1987, 1991). In this view, the aspects of human activity especially social activity are mediated by artifacts. These artifacts can include language, technology, tools, and signs. Communication technology is one such artifact which is having an impact both on the conduct and communication of scholarship. As Nyiri points out

Communication technologies from cave painting to the printed page have always influenced the very nature of the knowledge they communicated. (Nyiri, 2003, p. 56)

The consideration of how the mediation of activities affects human behavior is stated powerfully by Saljö.

Technological development runs through human history and it has contributed to changing our daily activities many times. Human learning has always been a matter of mastering tools of different types... we have to consider the unit we are studying is people in action using tools of some kind. (Saljö, 1999, p. 147)

The knowledge society as Castells points out is characterized

Not (by) the centrality of knowledge and information but by the application of such knowledge and information to knowledge generation and information processing/communications devices, in a cumulative feedback loop between innovation and the uses of innovation. (Castells, 1996, p. 32)

It is in the context of these commentaries that we need to consider the impact of the use of computing and communication technologies on scholarship. 


\section{CHALLENGES FOR DIGITAL SCHOLARSHIP}

There are set of challenges for researchers in the area to consider: I pose these as questions. Some of these have been discussed earlier, I would like to encourage submissions to this journal specialty on digital scholarship exploring these potential areas and other relevant research questions:

- What is meant by digital scholarship?

- What kinds of digital scholarship are engaging academics and researchers?

- How do academics learn digital scholarship practices within particular networks?

- How can institutions facilitate scholarship practices by enabling access to digital resources and supporting use of digital resources?

- How can digital scholarship practices challenge institutional structures and processes, for example, for promotion?

- How do specific media/devices/technologies mediate scholarship practices?

- How is new technology constructing the landscape influencing scholarly practices?

- Are there any aspects of the design of the new technological infrastructure that make this easier or harder?

- What roles do interactions with others facilitated by social networking play in this?

\section{REFERENCES}

Borgman, C. (2007). Scholarship in the Digital Age: Information, Infrastructure and the Internet. Cambridge, MA: MIT Press.

Boyer, E. (1990). Scholarship Reconsidered: Priorities of the Professoriate. Special report for the Carnegie Foundation for the Advancement of Teaching. Atlanta: Jossey Bass.

Boyer, E. (1994). A Community of Scholars. Keynote Address at Emory College, April 14th, In Selected Speeches 1979-1995 ERIC ED413293.

Castells, M. (1996). The Information Age: Economy, Society and Culture, Vol. 1, The Rise of the Networked Society. Oxford: Blackwell.

Colebeck, C., and Michael, P. (2006). The public scholarship: reintegrating Boyer's four domains. New Directions for Institutional Research 129: 7-19. doi:10.1002/ ir. 168

Engeström, Y. (1987). Learning by Expanding: An Activity-Theoretical Approach to Developmental Research. Helsinki: Orienta-Konsultit.

Engeström, Y. (1991). Activity theory and individual and social transformation. Multidisciplinary Newsletter for Activity Theory 7: 14-5.

Friesen, S., with Saar, C., Park, A., Marcotte, C., Hampshire, T., Martin, B., et al. (2016). Focus on Inquiry. Available at: http://www.inquiry.galileo.org

Glassick, C.E. (2000). Boyer's expanded definitions of scholarship, the standards for assessing scholarship, and the elusiveness of the scholarship of teaching. Academic Medicine 75: 877-80. doi:10.1097/00001888-20000900000007

Glassick, C.E., Huber, M.T., and Maeroff, G.I. (1997). Scholarship Assessed: Evaluation of the Professoriate. San Francisco: Jossey Bass.
- What consequences do these changes have for the professional practices of educators?

- What are the various new methods of dissemination/ engagement being developed?

- Are there different take up of findings (e.g., by publics or other groups) when publicized via these new methods?

- Are new approaches and technologies required for researching digital practices and artifacts?

- Do the various ways in which digital scholarship is conceptualized have implications for research designs?

\section{AUTHOR CONTRIBUTIONS}

The author confirms being the sole contributor of this work and approved it for publication.

\section{ACKNOWLEDGMENTS}

My thanks are due to colleagues involved in discussions about digital scholarship. These include Martin Weller, Katerina Avramides, Nick Pearce, Tim Coughlan, Robert Farrow, Jude Fransman, and Richard Holliman.

\section{FUNDING}

This work was funded by a grant from the Open University Strategic Research Fund.

Johnston, R. (1998). The university of the future: Boyer revisited. Higher Education 36: 253-72. doi:10.1023/A:1003264528930

McAndrew, P., Scanlon, E., and Clow, D. (2010). An open future for higher education. Educause Quarterly 33.

Nyiri, K. (2003). Towards a knowledge society. In DigiCULT. InforA Newsletter on Digital Culture 6. Available at: http://www.digicult.info

Pearce, N., Weller, M., Scanlon, E., and Kinsley, S. (2010). Digital scholarship considered: how new technologies could transform academic work. In Education 16. Available at: http://oro.open.ac.uk/24699

Säljö, R. (1999). "Learning as the use of tools: a sociocultural perspective on the human-technology link," in Learning with Computers: Analysing Productive Interaction, eds K. Littleton and P. Light (London: Routledge), 144-61.

Scanlon, E. (2013). Scholarship in the digital age: open educational resources, publication and public engagement. British Journal of Educational Technology 45: 12-23. doi:10.1111/bjet.12010

Conflict of Interest Statement: The author declares that the research was conducted in the absence of any commercial or financial relationships that could be construed as a potential conflict of interest.

Copyright (C) 2017 Scanlon. This is an open-access article distributed under the terms of the Creative Commons Attribution License (CC BY). The use, distribution or reproduction in other forums is permitted, provided the original author(s) or licensor are credited and that the original publication in this journal is cited, in accordance with accepted academic practice. No use, distribution or reproduction is permitted which does not comply with these terms. 